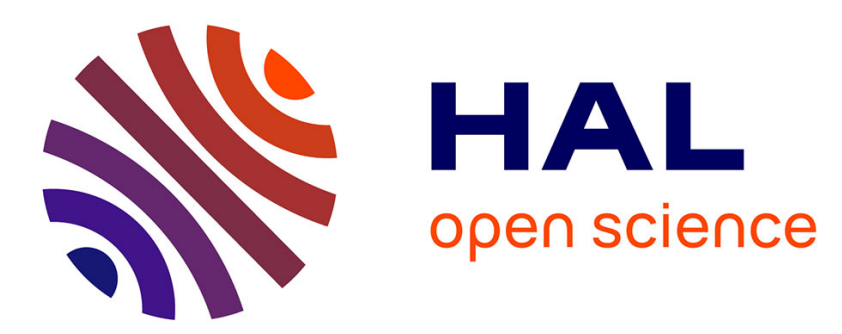

\title{
A review on the martensitic transformation and shape memory effect in Fe-Mn-Si alloys
}

Q. Gu, J. van Humbeeck, L. Delaey

\section{To cite this version:}

Q. Gu, J. van Humbeeck, L. Delaey. A review on the martensitic transformation and shape memory effect in Fe-Mn-Si alloys. Journal de Physique IV Proceedings, 1994, 04 (C3), pp.C3-135-C3-144. 10.1051/jp4:1994319 . jpa-00252516

\section{HAL Id: jpa-00252516 https://hal.science/jpa-00252516}

Submitted on 1 Jan 1994

HAL is a multi-disciplinary open access archive for the deposit and dissemination of scientific research documents, whether they are published or not. The documents may come from teaching and research institutions in France or abroad, or from public or private research centers.
L'archive ouverte pluridisciplinaire HAL, est destinée au dépôt et à la diffusion de documents scientifiques de niveau recherche, publiés ou non, émanant des établissements d'enseignement et de recherche français ou étrangers, des laboratoires publics ou privés. 


\title{
A review on the martensitic transformation and shape memory effect in Fe-Mn-Si alloys
}

\author{
Q. GU, J. VAN HUMBEECK and L. DELAEY
}

Dept. of Metallurgy and Materials Engineering, K.U. Leuven De Croylaan 2, 3001 Leuven, Belgium

\begin{abstract}
The martensitic transformation and the shape memory effect in Fe-Mn-Si alloys received great attention recently due to its potential commercial value. In this paper, the mechanisms for the martensitic transformation and various parameters influencing the shape memory effect like alloy composition, applied stress, prestrain, crystal orientation, temperature, grain size, pre-existing martensite, thermal cycling and training etc. are reviewed and discussed.
\end{abstract}

The shape memory effect has been found in many Fe-based alloys like Fe-Ni[1], $\mathrm{Fe}-\mathrm{Cr}-\mathrm{Ni}[2,3], \mathrm{Fe}-$ $\mathrm{Mn}[4,5], \mathrm{Fe}-\mathrm{Mn}-\mathrm{Si}[6-10]$ alloys. In contrast to traditional Ni-Ti or Cu-based shape memory alloys, the martensitic transformation involved in this alloy is non-thermoelastic and with quite large hysteresis. The range $M_{s}-A_{f}$ is usually around $100^{\circ} \mathrm{C}$. The austenite to $\varepsilon$-martensite transformation is believed to proceed by the $a / 6[112]$ Shockley partial dislocations trailing a stacking fault ribbon moving on every other $\{111\}$ austenite plane and changing the crystal structure to martensite. The shape memory effect, which is of the one way type, is mainly resulting from a reverse motion of the Shockley partial dislocations during heating. The complete shape memory effect has been reached in both single crystal[7,8] and polycrystalline[9,10] $\mathrm{Fe}-\mathrm{Mn}-\mathrm{Si}$ alloys with a suitable combination of $\mathrm{Mn}$ and $\mathrm{Si}$ contents. A $9 \%$ shape memory strain in single crystals [8] and 5\% in polycrystals[9] has been reported. The mechanism for martensitic transformation and shape memory effect in Fe-Mn-Si alloys, the various parameters influencing the shape memory effect are reviewed and discussed.

\section{Martensitic transformation}

With the change of alloy compositions in Fe-Mn-Si alloys, the austenite (f.c.c structure) parent phase can transform to $\varepsilon$-martensite (h.c.p structure) or $\alpha^{\prime}$-martensite (b.c.t structure) by simple cooling or deformation. In extra-low carbon containing manganese steels, if $\mathrm{Mn}$ is lower than $10 \%$, only $\alpha^{\prime}$ martensite occurs, between 10 to $15 \% \mathrm{Mn}$ both $\alpha^{\prime}$ and $\varepsilon$-martensite occur, and above $15 \% \mathrm{Mn}, \alpha^{\prime}-$ martensite disappears and $\gamma$ to $\varepsilon$ transformation dominates. A metastable Fe-Mn phase diagram can be drawn in which the $\gamma$ to $\varepsilon$ or $\gamma$ to $\alpha^{\prime}$ transformation temperatures are given. The $\alpha^{\prime}$-martensite can be formed in the $\varepsilon$-martensite, indicating that $\gamma \rightarrow \varepsilon \rightarrow \alpha^{\prime}$ transformation is also possible[13]. 
The $\gamma$ to $\varepsilon$ martensitic transformation mechanism has been studied by several authors[14-16]. The transformation is conducted by the splitting of a perfect dislocation in $\gamma$ phase into two Shockley partial dislocations and with a stacking fault between them. By the motion of Shockley partial dislocations in every other $\{111\}$ of austenite, a change in the stacking sequence is obtained through a (111) $[112]_{\gamma}$ shear. A bulk hep crystal with $\{111\}_{\gamma} / /\{0001\}_{s},[110]_{\gamma} / /[11 \overline{2} 0]_{\varepsilon}$ orientation relationship is produced. Currently two mechanisms for forming $\varepsilon$-martensite by Shockley partial dislocations are proposed.

The operation of a pole mechanism, which is the multiplication of partial dislocations and occurs on every second $\{111\}$ austenite plane to form $\varepsilon$-martensite directly, is observed in an Fe-31Mn-6Si(wt\%) single crystal[14]. By in-situ observation of partial dislocation motion during $\gamma$ to $\varepsilon$ martensitic transformation, it is found that a small angle boundary composed of three types of perfect dislocations acts as a dislocation source. A pole dislocation is generated by the following dislocation reaction:

$$
(\mathrm{a} / 2)[1 \overline{1} 0]+(\mathrm{a} / 2)[011]+(\mathrm{a} / 2)[0 \overline{1} 1] \rightarrow(2 \mathrm{a} / 3)[1 \overline{1} 1]+(\mathrm{a} / 6)[\overline{1} 12]
$$

and $(2 \mathrm{a} / 3)[1 \overline{1} 1]$ is the pole dislocation as proposed by Seeger. The multiplication of the piled up partial dislocations finally generates an $\varepsilon$-martensite. In the stacking fault mechanism, stacking faults are introduced in the $\{111\}$ planes of austenite by the passage of the a/6 Shockley partial dislocations, forming actually a hcp structure[15,16]. Therefore, they can be considered as a nucleus of $\varepsilon$ martensite. By further cooling or deformation, they will grow into thicker $\varepsilon$-martensite plates. This mechanism is divided into three stages[17]. First is the formation of a wide stacking fault, second is the irregular overlapping of wide stacking faults, third is the regular overlapping of these stacking faults on every other $\{111\}_{\gamma}$ slip plane to form an $\varepsilon$-martensite. Since the stacking fault energy in Fe-Mn-Si alloys is usually quite low, the perfect dislocations on $\{111\}_{\gamma}$ planes with a Burgers vector a/2[110] can easily split into two a/6[211 $]_{\gamma}$ Shockley partial dislocations. A wide stacking fault is left between them. The further extension and overlapping of the stacking faults by the motion of those partial dislocations result in the formation of $\varepsilon$-martensite. This mechanism is supported by Inagaki[15] and $\mathrm{Li}[16]$ based on their observations of martensitic transformation in a $\mathrm{Fe}-14 \mathrm{Mn}-6 \mathrm{Si}-9 \mathrm{Cr}-6 \mathrm{Ni}(\mathrm{wt} \%$ ) alloy and $\mathrm{Fe}-32 \mathrm{Mn}-6 \mathrm{Si}-0.04 \mathrm{C}-0.05 \mathrm{Nb}$ (wt\%) alloy respectively.

\section{THE SHAPE MEMORY EFFECT}

The shape memory effect results from the reverse motion of Shockley partial dislocations which transform stress-induced $\varepsilon$-martensite back to austenite. Any factors impeding the reversibility of the motion of partial dislocations will lead to an incomplete recovery and in turn to a poor shape memory effect. There exist many internal and external parameters influencing the shape memory effect. The internal factors are alloy compositions, Néel temperature, transformation temperatures etc. These factors determine the physical and mechanical properties of the alloy. The external factors are applied stress and strain, annealing and quenching temperature, deformation and recovery annealing temperature, thermomechanical treatment etc. Moreover, crystal orientation, grain size, pre-existing martensite, cycling and training and the accompanying $\varepsilon$ to $\alpha^{\prime}$ transformation also influence the shape memory effect. 


\section{Influence of alloy compositions}

The shape memory effect in Fe-Mn-Si alloy strongly depends on the alloy composition. It has been reported $[18,19]$ that a complete shape memory effect can only be reached in a single crystal and polycrystal by a suitable combination of $\mathrm{Mn}$ and $\mathrm{Si}$ content. There are four points in considering the kind and content of alloy compositions in $\mathrm{Fe}-\mathrm{Mn}$-Si alloys regarding their functions in obtaining good a shape memory effect and additional properties: 1) Parent phase forming elements for forming austenite phase and avoiding $\alpha^{\prime}$ and $\sigma$ phase: $\mathrm{Fe}, \mathrm{Mn}$; 2) Solution hardening elements to increase the yield stress of austenite parent phase for preventing the intrusion of permanent slip during the deformation: The degree of solution hardening of the $\gamma$ matrix is increased in the following order[2023]: substitutionally dissolved $\gamma$-forming elements: $\mathrm{Ni}, \mathrm{Mn}$; substitutionally dissolved ferrite-forming elements: $\mathrm{Si}, \mathrm{Cr}$ and $\mathrm{Al}$; and interstitially dissolved elements: $\mathrm{C}, \mathrm{N}$ (They harden the $\gamma$ matrix efficiently, but should be as low as possible to avoid the formation of carbides or nitrides which hamper the shape memory effect); 3) Anticorrosion elements for improving the corrosion resistance: $\mathrm{Cr}, \mathrm{Si}$; 4) Elements influencing the Nêel temperature: $\mathrm{Mn}$

$\mathrm{Mn}$ is a strongly $\gamma$-forming element. If the Mn content is above $20 \%$, the $\alpha$-martensite formation is avoided. But too much $\mathrm{Mn}$ will deteriorate the corrosion resistance and the high-temperature oxidation resistance. When $\mathrm{Mn}$ content is less than $15 \%$, the precipitation of $\sigma$ phase is inhibited. In addition, with the increase of $M n$ content, the NEel temperature is raised and $M_{s}$ temperature is depressed[19].

Si increases the strength of the $\gamma$ matrix and high-temperature oxidation resistance. Meanwhile, it also decreases the Néel temperature without changing the $\mathbf{M}_{s}$ temperature. Moreover, it diminishes the stability of $\gamma$ phase and lower the stacking fault energy in austenite. But too much of it will largely decrease the cold and hot workability and ductility. Murakami et al[19] and Tsuzaki et al[24] conclude from their investigations that the addition of Si plays an important role in the reversible movement of Shockley partial distocations. It can make those partial dislocations reversible and restrict the permanent slip in austenite during a shape change. But, Murakami[19] also found that in $\mathrm{Fe}-\mathrm{Mn}-\mathrm{Si}$ alloys if $\mathrm{Si}$ addition is over $6.5 \%$, the alloy became very brittle and can hardly be deformed in bending tests.

Cr improves the corrosion resistance, high-temperature oxidation resistance and yield stress. But too much addition will cause ferrite formation. If $\mathrm{Cr}$ is less than $11 \%$, the ferrite phase can be prevented. By increasing the $\mathrm{Cr}$ content, the Neel temperature, $\mathrm{M}_{s}$ temperature and the stacking fault energy is decreased. The limitation of $\mathrm{Cr}$ content is $20 \%$, otherwise, the formation of $\delta$ phase will deteriorate the workability, toughness and shape memory effect of the alloy.

$\mathrm{Ni}$ is added to inhibit the formation of ferrite without enhancing the precipitation of $\sigma$ phase and to stabilize the $\gamma$ phase. Too much of it will depress the $M_{s}$ temperature.

$\mathrm{Cu}$ is a $\gamma$-forming element. It improves the corrosion resistance and increases the stacking fault energy. When the addition is over $3 \%, \varepsilon$-martensite transformation is suppressed.

$\mathrm{N}$ improves the corrosion resistance and the yield strength of the matrix. If the addition is over $0.4 \%$, it will cause the formation of nitrides of $\mathrm{Cr}$ and $\mathrm{Si}$.

$\mathbf{P}, \mathbf{S}$ are impurities and it is advisable to limit them below $0.1 \%$. 


\section{Influence of Néel temperature}

Since the antiferromagnetic ordering of $\gamma$ phase will strongly stabilise the $\gamma$ phase, the $\varepsilon$-martensite transformation will be largely depressed. A suitable combination of Néel temperature $T_{n}, M_{s}$ and deformation temperature must be reached in order to get a good shape memory effect. $T_{n}$ should be far below $\mathbf{M}_{s}$ temperature and $\mathbf{M}_{s}$ should be just below the deformation temperature. If $\mathbf{M}_{s}$ is high, the spontaneous formation of thermal martensite in the alloy will suppress the stress-induced martensitic transformation. However, if $\mathrm{M}_{s}$ is far below the deformation temperature, a very large chemical driving force is needed for the stress-induced martensitic transformation.

\section{Influence of applied stress}

With the increase of applied stress, the magnitude of the total recovery in an Fe-30Mn-1Si single crystal decreased continuously. This indicates that with a small applied stress only the primary shear system is induced by deformation. When the applied stress increases, the other shear systems are also in operation. Due to the interaction of these primary and non primary shear systems, the reverse motion of Shockley partial dislocations are hindered. The shape recovery is depressed. The yield stress is also temperature dependent[25]. Below $T_{0}$, the temperature at which the free energy of austenite and martensite is equal, the martensite can be stress-induced. And the critical stress for martensite transformation is positive temperature dependent. Above $T_{0}$ temperature, the critical stress for slip deformation is decreased with increasing temperature. In order to generate martensite without introducing slip deformation, special care in choosing the deformation temperature is needed. In some alloys below a certain temperature, a negative critical stress temperature dependence appears again [26]. This turning point temperature usually corresponds with the $M_{f}$ temperature of the alloy. It means that further deformation in the martensite phase at lower temperature needs a higher applied stress. A higher yield stress level is observed in polycrystals. As suggested by Sato[26] this is partly due to the smaller Schmid factor and partly to the higher work hardening rate.

\section{Influence of prestrain}

The amount of prestrain applied has a strong influence on the shape memory effect of the alloy. When the prestrain is small, as only primary $\varepsilon$ variants are induced by the deformation, the recovery is usually complete since the reverse motion of Shockley partial dislocations are not hindered. When a large prestrain is applied, the different orientations of $\varepsilon$ variants operate in the structure. The intersection of these $\varepsilon$-martensites will obstruct the backward motion of partials. Robinson et al[9] found that a maximum shape memory strain is obtained at a prestrain of $4 \%$. The prestrain increases both the stress required for slip and the stress required for the movement of partial dislocations associated with the transformation. In some circumstances, at small strain level, the stress for slip is more sensitive to the level of prestrain. 
Sato[27] has studied the stress-strain behavior of single crystals with different crystal orientation and polycrystalline material at various temperatures in a Fe-Mn-Si alloys. He concludes: 1) Work hardening rate at small strain is much greater in polycrystals than in single crystals; 2) Ductility decreases while ultimate strength increases notably as temperature becomes lower; 3) Yield stress of polycrystals increases with decrease in temperature.

Although the yield stress in polycrystals is higher than that in single crystals, the shape memory strain obtained in single crystals is much higher than that in polycrystals. A $9 \%$ shape memory strain in single crystals is reported[8] while in polycrystals only around $5 \%$ is reported[9], indicating the crystal orientation must play an important role in the formation of $\varepsilon$-martensite. The shape memory effect is suppressed in [001] tension compared with the nearly perfect shape memory effect in [414] tension[27]. This suggests that the operation of $\varepsilon$ variants on more than two types of $\{111\}$ plane in [001] tension is the reason for the suppression of the shape memory effect.

\section{Influence of annealing temperature}

The annealing of the alloy at high temperature changes structures and properties of the alloy in three ways. First, it changes the transformation temperature. With the increase of annealing temperature, $M_{s}$ temperature increases and $A_{s}$ temperature decreases. Robinson et al[28] reported in their study of Fe-30Mn-7Si alloy that annealing at temperatures above $1000 \mathrm{~K}$ resulted in a substantial increase in both transformation and permanent strain. They related this behavior to recrystallization. Second, annealing removes the work hardened structure caused from rolling. The study of the effect of quenching temperature on the shape memory effect in Fe-30Mn-5Si and Fe-23Mn-3Si by Zhao et al[29], shows that increasing the quenching temperature rises $M_{s}$ remarkably but $A_{s}$ changes little. The reasons for this behaviour, as suggested by Nishiyama[30], is that a higher quenching temperature produces more frozen-in vacancies and hence more nucleation sites. Secondly, a possibly more likely reason, is that annealing at higher temperature may eliminate the lattice imperfections and reduce the energy required for the complementary shear during transformation.

\section{Influence of deformation temperature}

The temperature of deformation is another very important factor. The deformation temperature must be between $M_{s}$ temperature and $T_{0}$ temperature in order to induce $\varepsilon$-martensite. The prestrain at elevated temperature can improve the shape memory effect through strain hardening the parent phase. Robinson et al[9] prestrained the alloy by $4 \%$ at $523 \mathrm{~K}$ and improved the transformation strain from 2.4 to $3 \%$. Similar results are also reported by Murakami[31]. Sato et al[27] reported that the shape memory effect is very sensitive to the deformation temperature. The $\mathbf{M}_{\mathrm{s}}$ and $\mathrm{T}_{0}$ temperature of an Fe$27 \mathrm{Mn}-3 \mathrm{Si}(\mathrm{wt} \%)$ alloy are $339 \mathrm{~K}$ and $414 \mathrm{~K}$ respectively. The shape memory effect is only obtained between a temperature range of $360 \mathrm{~K}-380 \mathrm{~K}$. Recently it has been reported by Yang[32] et al that by deformation of $\mathrm{Fe}-\mathrm{Mn}$-Si alloys at very low temperature, like $77 \mathrm{~K}$, a better shape memory effect was obtained. The already formed spontancous thermal $\varepsilon$-martensite suppresses the formation of induced $\varepsilon$ - 
martensite. Due to the large undercooling and applied stress, the pre-existing martensite may start a reorientation process. The pre-existing martensite with preferred orientation will grow. There will be less obstacles in confronting the formation and growth of stress-induced $\varepsilon$-martensite. Particularly, it is known that in $\gamma$ to $\varepsilon$ transformation, the stacking fault energy decreases with decreasing temperature.

\section{Influence of recovery annealing temperature}

The influence of recovery annealing temperature is obvious. The higher it is, the larger the driving force it can provide to the complete recovery of $\varepsilon$-martensite.

\section{Influence of grain size}

The influence of grain size is still not well understood. According to Tan et al[33], in an Fe-29Mn-6Si alloy the increase of grain size decreases the shape memory effect. The coarser the grain sizes, the higher the stress concentrations that will be built up. When the local stress near the grain boundaries exceeds the critical resolved shear stress for usual slip, a a/2[110] perfect dislocation will be formed within the grain. The shape memory effect is therefore suppressed. However the study on an Fe-32Mn$6 \mathrm{Si}$ alloy by Murakami[31] has shown that no distinguishable difference was observed in the shape memory effect with the variation of grain size from $20-200 \mu \mathrm{m}$.

\section{Influence of pre-existing $\varepsilon$-martensite}

When the $\mathbf{M}_{s}$ temperature is above room temperature, always a certain amount of $\varepsilon$-martensite is formed. The distribution and amount of these pre-existing $\varepsilon$-martensites is believed to have large influence on the shape memory effect. By means of a two step tensile deformation, Sato et al conducted an investigation on an Fe-30Mn-1Si alloy[34]. It is shown that the flow stress is largely increased in the second step. The $\varepsilon$-martensite induced by the first step acts as a strong obstacle against the motion of partial as well as perfect dislocations. TEM showed that this large hardening is solely coming from the strong blocking by the pre-injected $\varepsilon$-martensite. Zhao et al[29] suggested that the influence of pre-existing $\varepsilon$-martensite is dual. They will strengthen the matrix and inhibit the intrusion of permanent slip during deformation. They will also suppress the stress induced martensitic transformation to a certain extent due to the $\varepsilon$-plates intersection. The microstructural observation shows that when quenched from $600^{\circ} \mathrm{C}$ and $1000^{\circ} \mathrm{C}$ respectively, $\varepsilon$-plates are only formed in one direction in the former specimen, but bundles of intersected $\varepsilon$-plates inside one grain are formed in the later one. The shape memory effect is decreased from $55 \%$ recovery to $45 \%$ with the increase of quenching temperature.

\section{Influence of thermal cycling}

Gosh et al[35] have studied the effect of thermal cycling in Fe-(26-32)Mn-(3-6)Si alloy and found that the amount of $\varepsilon$-martensite detected at room temperature significantly increased by thermal 
cycling between room temperature and 573K. Tsuzaki et al[24] reported on an Fe-24Mn-6Si alloy by thermal cycling between $273 \mathrm{~K}, 305 \mathrm{~K}$ and $573 \mathrm{~K}, 873 \mathrm{~K}$. It is observed that the $\mathrm{M}_{\mathrm{s}}$ temperature slightly decreases with increasing number of cycling. The $A_{s}$ temperature is almost constant. The amount of $\varepsilon-$ martensite at $305 \mathrm{~K}$ is markedly increased by cycling. However, the enhancement of $\varepsilon$-martensite is not found by thermal cycling between $305 \mathrm{~K}$ and $875 \mathrm{~K}, 1173 \mathrm{~K}$. The microstructure memory and $\gamma$ strength has been found to increase when thermal cycling is conducted with an upper peak temperature of $573 \mathrm{~K}$. But the microstructure memory is lost at $875 \mathrm{~K}$ cycling which they believed is due to the recovery of $\gamma$, dislocation climbing and rearrangement frequently occurring at $875 \mathrm{~K}$.

A different situation is reported by Sade et al[36] in the study of Fe-(24-35)Mn-(2-5)Si alloy by thermal cycling between $-196^{\circ} \mathrm{C}$ and $325^{\circ} \mathrm{C}$. The $\mathrm{M}_{s}$ temperature is lowered about $10 \mathrm{~K}$ and $\mathrm{A}_{s}$ temperature is raised remarkably. Hysteresis is increased by thermal cycling. It suggests that sessile lattice defects like dislocations and stacking faults are produced. They will impede the motion of Shockley partial dislocations in the transformation interface.

\section{Influence of training}

Recently the influence of training on the shape memory effect received great attention since it improves the shape memory strain greatly[37-39]. The training can suppress the slip deformation through the work hardening introduced by dislocations, and lower the stress for inducing $\varepsilon$-martensite through introducing the stacking faults which can act as nucleation embryos for $\varepsilon$-martensite. Otsuka et al obtained a temperature dependence of the yield stress before and after training in an Fe-20Mn-5Si$8 \mathrm{Cr}-5 \mathrm{Ni}$ alloy[39]. The stress for slip deformation is increased and the stress to induce the martensitic transformation is decreased by the training. The training consists of repeating 2-3\% deformation and annealing at $873 \mathrm{~K}$. The amount of strain and the temperature of annealing employed in training is quite important in determining the shape memory effect. During training an Fe-32Mn-6Si alloy[25], the temperature of annealing is found to be critical for the improvement of shape memory effect. Annealing at $873 \mathrm{~K}$ is found to be most effective in improving the shape memory effect. If the annealing temperature is lower than $873 \mathrm{~K}$, only suppression of slip deformation is obtainable. If annealing is much higher than $873 \mathrm{~K}$, only the generation of $\varepsilon$-martensite at low stress is obtainable.

\section{Two way shape memory effect}

Two way shape memory effect has been also observed in Fe-Mn-Si alloys, but only for very small values. An Fe-29Mn-6Si alloy shows a small magnitude of two way shape memory effect by training, which consisted of bending deformation at $253 \mathrm{~K}$ and annealing at $673 \mathrm{~K}$ [40]. The orientation degree of $\varepsilon$-martensite is suggested to be increased through training. The two way shape memory effect is also found in an Fe-24Mn-6Si alloy and the occurrence strongly depends on the upper temperature of cyclic heating[41]. It appears when the upper temperature is $573 \mathrm{~K}$ and it disappears when the upper temperature is $873 \mathrm{~K}$. 
$\gamma \rightarrow \varepsilon \rightarrow \alpha^{\prime}$ transformation

Accompanying the $\varepsilon$ martensitic transformation, the $\boldsymbol{\gamma} \rightarrow \boldsymbol{\varepsilon} \rightarrow \boldsymbol{\alpha}$ transformation is also found in some Fe-Mn-Si alloys[13,14] depending on the alloy composition and the amount of deformation applied. An optical color micrograph showing the $\gamma \rightarrow \varepsilon \rightarrow \alpha^{\prime}$ transformation in an Fe-16Mn-5Si-9Cr-4Ni alloys after $5 \%$ compression deformation is shown in fig. 1 .

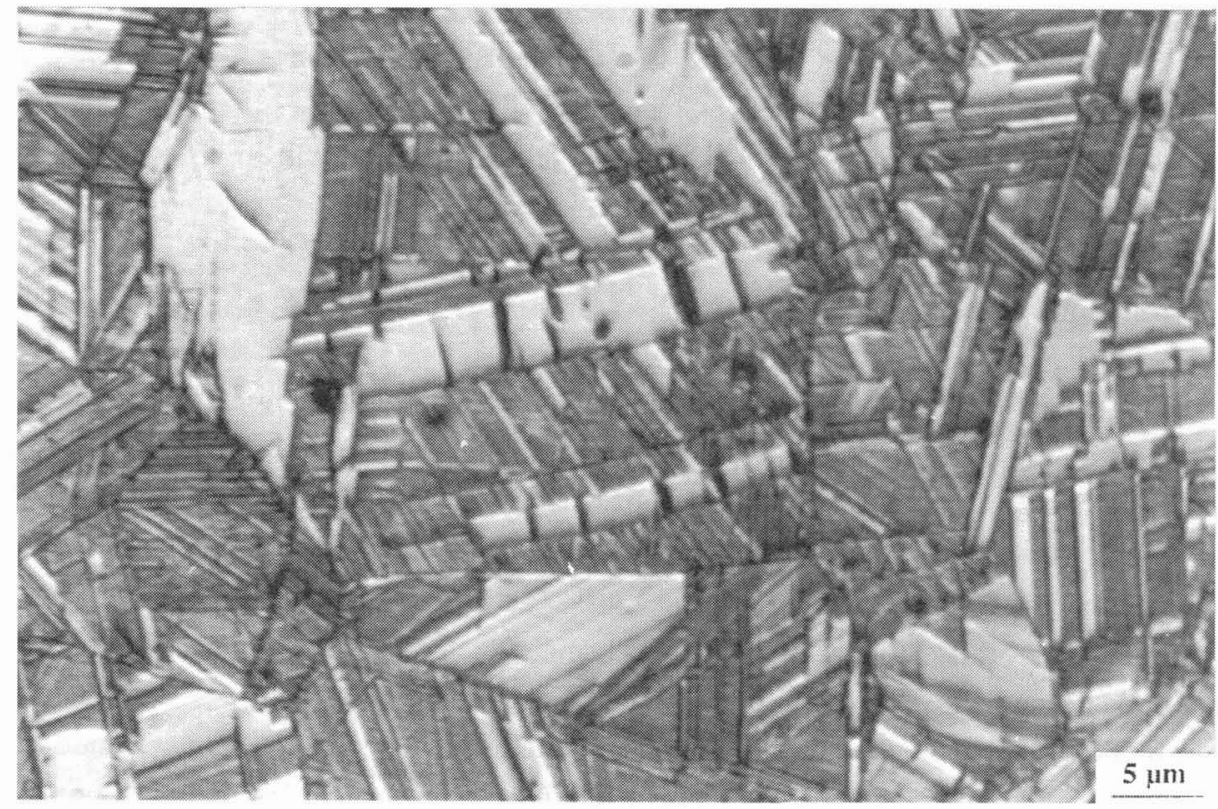

Fig.1 Optical micrograph of an Fe-16Mn-5Si-9Cr-4Ni alloy after 5\% compression deformation showing $\gamma \rightarrow \varepsilon \rightarrow \alpha^{\prime}$ transformation, here $\varepsilon$-martensite is etched as white plate, $\gamma$ as yellow matrix and needle -like plates inside $\varepsilon$-martensite are $\alpha^{\prime}$ martensite

The suppression of $\alpha^{\prime}$-martensite in an Fe-31Mn-6Si alloy is important for improving the shape memory effect[14]. In the region where $\varepsilon$-martensites are cutting each other, small $\alpha^{\prime}$-martensites were found to form at the intersections. TEM observation shows that the partial dislocations are affected strongly by the presence of other $\varepsilon$ and $\alpha^{\prime}$-martensites. The $\varepsilon$-martensites bound by $\alpha^{\prime}$-martensites at the ends are stable against heating up to $673 \mathrm{~K}$. 


\section{CONCLUDING REMARKS}

To obtain a optimum shape memory effect, following points should be considered:

1) A suitable combination of alloy composition

2) Deformation must take place only by stress-induced $\varepsilon$-martensite transformation without accompanying slip. If deformation is conducted at room temperature, as most practical application does, the $M_{s}$ temperature must be just below room temperature.

3) The Nél temperature must be below $M_{s}$ temperature and as low as possible, since the antiferromagnetic ordering of $\gamma$ phase will strongly stabilise the $\gamma$ phase and suppress the $\varepsilon$ martensite transformation.

4) The yield stress of austenite parent phase should be as high as possible to avoid slip deformation.

5) The stress induced $\alpha^{\prime}$-martensite transformation, which may deteriorate the shape memory effect, must be prevented. Therefore the stacking fault energy of $\gamma$ parent phase should be as low as possible.

\section{ACKNOWLEDGEMENTS}

Q. Gu thanks the Dept. of Metallurgy and Materials Engineering for providing a research scholarship. Part of his work is financed by the CECA-project 7210/MA/314, in collaboration with Ugine-Savoie (France) and INSA-Lyon (France). The authors appreciate the valuable discussions with Dr. W. J. Yang. J. Van Humbeeck acknowledges the National Science Foundation of Belgium.

\section{REFERENCES}

/1/ S. Kajiwara, Phil. Mag. A41 (1980) 403

/2/ A. Sato, E. Chishima, K. Soma and T. Mori, Proc. ICOMT-79, (1979) 183

13/ K. Enami, A. Nagasawa and S. Nenno, Scripta Metall., 9 (1982) 941

/4/ K. Enami, A. Nagasawa and S. Nenno, Scripta Metall., 9 (1975) 941

15/ K. Adachi and J. Perkins: Metall. Trans. A, 17A (1986) 945

/6/ J. Van Humbeeck, J. Stoiber and R. Gotthardt, Proc. ICIFUAS-9, (1989) 321

/7/ A. Sato, K. Soma, E. Chishima and T. Mori, J. Physique, 12 C4 (1982)797

18/ A. Sato, E. Chishima, K. Soma and T. Mori, Acta metall., 30 (1982) 1177

19/ J. S. Robinson and P. G. McCormick, Mat. Sci. Forum, 56 (1990) 649

/10/ A. Sato: MRS Int'1. Mtg. on Adv. Mats., 9 (1989) 431

/11/H. Schumann, Arch. Einsenhutt., 38 (1967) 647

/12/ A. R. Troiano and F. T. Mcguire, Trans. ASM, 31 (1943) 340

/13/ W. J. Yang, PH.D thesis, Chosun Univ., Korea, (1991) 53

/14/ Y. Hoshino, S. Nakamura, N. Ishikawa, Y. Yamaji, S. Matsumoto, Y. Tanaka and A. Sato, Mat. Trans., JM, 33 (1992) 253

/15/ H. Inagaki, Z. Metallkd,, 83 (1992) 90

/16/ J. Li and C. M. Wayman, Scripta Metall., 27 (1992) 279

/17/ H. Fujita and S. Ueda, Acta. metall., 20 (1972) 759

/18/ A. Sato, Y. Yamaji and T. Mori, Acta. Metall., 34 (1986) 287 
/19/ M. Murakami, H. Otsuka, H. G. Suzuki and S. Matsuda, Proc. ICOMT-86, (1986) 985

/20/ K. J. Irvine, D. T. Liewellyn and F. B. Pickering, JISI, (1961) 153

/21/ European Patent Application, 0336157, (1989)

122/ European Patent Application, 0336175, (1989)

/23/ Y. Moriya, H. Suzuki, S. Hashizume, T. Sampei and I. Kozasu, Proc. ICSS, (1991) 527

124/ K. Tsuzaki, M. Ikegami, Y. Tomota, Y. Kurokawa, W. Nakagawara and T. Maki, Mat. Tans., JIM, 33 (1992) 263

125/ H. Otsuka, M. Murakami and S. Matsuda, MRS Int'1. Mtg. on Adv. Mats., 9 (1989) 451

126/ A. Sato, K. Takagaki, S. Horie, M. Sato and T. Mori, Proc. ICOMT-86, (1986) 979

127/ A. Sato, E. Chishima, Y. Yamaji and T. Mori, Acta. Metall., 32 (1984) 539

/28/ J. S. Robinson and P. G. McCormick, Mat. Sci. Forum, 56 (1990) 649

129/ Q. H. Zhao and S. S. Tan, Acta. Metall. Sinca., A2 (1989) 228

130/ Z. Nishiyama, Martensitic Transformation, ed. by Academic Press, (1978) 306

131/ M. Murakami, H. Otsuka and S. Matsuda, Trans. ISIJ, B (1987) 87

132/ J. H. Yang, H. Chen and C. M. Wayman, Metall. Trans., 23A (1992) 1431

133/ S. M. Tan, J. H. Lao and S. W. Yang, Scripte Metall., 25 (1991) 2613

134/ A. Sato, K. Soma and T. Mori, Acta. Metall., 30 (1982) 1901

135/G. Ghosh, Y. Vanderveken, J. Van Humbeeck, M. Chandrasekaran, L. Delaey and W. Vanmoorleghem, MRS Int'l. Mtg. on Adv. Mats., 9 (1989) 457

136/ M. Sade, K. Halter and E. Hornbogen, Z. Metallkde, 79 (1988) 487

137/ H. Otsuka, M. Murakami and S. Matsuda, MRS Int'l. Mtg. on Adv. Mats., 9 (1989) 451

/38/ Y. Moriya, H. Kimura, S. Ishizaki, S. Hashizume, S. Suzuki, H. Suzuki and T. Sampei, Proc.

Euro. Sym. on Martensitic Transformation, C4 (1991) 433

139/ H. Otsuka, H. Yamada, T. Maruyama, H. Tanahashi, S. Matsuda and M. Murakami, Trans. ISIJ, $30(1990) 674$

/40/ S. M. Tan, J. H. Lao and S. W. Yang, Scripta Metall., 25 (1991) 1119

/41/ Y.Tomota, W. Nakagawara, K. Tsuzaki, and T. Maki, Scripta Metall., 26 (1992) 1571 